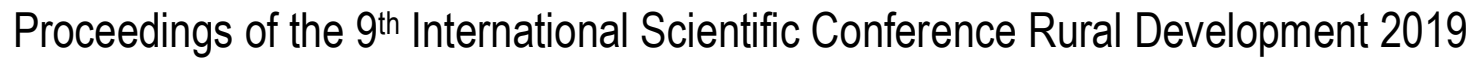

\author{
Edited by prof. Asta Raupelienè
}

ISSN 1822-3230 (Print)

ISSN 2345-0916 (Online)

\section{HERBS AS A SOURCE OF NATURAL PRESERVATIVES AGAINST RANCIDITY IN THE LOW-MOISTURE BAKERY PRODUCTS}

\begin{abstract}
Kateryna IORGACHOVA, Department of bread, confectionary, pasta and food concentrates technologies, Faculty of grain technology and grain business, Odessa National Academy of Food Technologies, 112, Kanatna Street, Odessa, Ukraine, 65039, iorgachova@ gmail.com Olga MAKAROVA, Department of bread, confectionary, pasta and food concentrates technologies, Faculty of grain technology and grain business, Odessa National Academy of Food Technologies, 112, Kanatna Street, Odessa, Ukraine, 65039, olga-odes@ukr.net

Nataliia SOKOLOVA, Department of bread, confectionary, pasta and food concentrates technologies, Faculty of grain technology and grain business, Odessa National Academy of Food Technologies, 112, Kanatna Street, Odessa, Ukraine, 65039, techinstoffood@ gmail.com Kateryna KHVOSTENKO, Department of bread, confectionary, pasta and food concentrates technologies, Faculty of grain technology and grain business, Odessa National Academy of Food Technologies, 112, Kanatna Street, Odessa, Ukraine, 65039, katekhvostenko@gmail.com (corresponding author)

In recent years, it is a global trend of avoiding the use of synthetic ingredients for the food products quality enhancement. In this case it is actual task to search for the alternative natural raw materials, which provide the stabilization the products quality during storage. Due to their chemical composition, physiological and functional-technological properties the usage of herbs is a perspective solution of this problem. The aim of the study was to evaluate the effectiveness of natural ingredients based on herbs (powder and extracts) on the rancidity retardation. The antioxidant effect of herb raw-materials (hop, chamomile, nettle) was studied for the low-moisture bakery products with high fat content. These products are the ideal type of "food on the go" with long term of storage, which characterized with increasing popularity among modern consumers. The study was conducted at the Odessa National Academy of Food Technologies labs. The peroxide value of samples was determined by iodometric method (ISO 3960:2017). The results revealed that addition of natural antioxidants to the bakery goods in comparison to products without additives reduced this indicator up to the $37 \ldots .52 \%$ for the samples with herbs. It has been determined that hop, chamomile and nettle incorporation have pronounced antiseptic properties also. The use of herbs in the low-moisture bakery products technology leads to the quality stabilization during their shelf life, improvement of nutritional value and it may be more attractive to consumers due to their natural origin.
\end{abstract}

Keywords: herbs, low-moisture bakery products, quality, rancidity.

\section{INTRODUCTION}

Preservation of the original high-quality product characteristics during the whole period of storage is a consumer preference that determines their demand and, therefore, the competitiveness of products on the market. During storage a number of changes lead to the products quality deterioration. The factors, which provide negative effect on the qualitative characteristics of bread, are caused by the moisture loss, aging of high polymeric substances - starch and proteins - as a result of complex physical, chemical and colloidal processes and microbial spoilage (Cauvain, 2015; Hebeda, 1996). Also, the lipid oxidation is a major problem for the quality stabilization of baked goods during their shelf-life, especially, for products with high fat content and long storage term.

Lipid oxidation is a process that results in rancidity and deterioration of fats and progresses via free-radical propagated chain reactions. Primary lipid oxidation provides forming of hydroperoxides that cause a variety of secondary reactions with evolution of aldehydes, ketones, acids, and other low-molecular-weight volatile substances (Ramis-Ramos, 2003). The presence of oxygen and metal ions, heat and light catalyze these processes (Dhartiben et. Al., 2016). Oxidative changes can cause rancidity such as of flavor, loss of color, altered nutrient value, which limits the shelf life of baked products, and may produce toxic compounds with mutagenic, carcinogenic and cytotoxic properties, which have detrimental consequences on consumer's health (Frankel, 2012; Mukhtair et. Al., 2016). Due to this oxidation of lipids is a serious concern for food industry, especially for long-term flour products.

Application of antioxidants is one of the most effective ways for the oxidation prevention and food shelf-life prolongation. Antioxidants are classified according to their origin, type of action and source of solubility (Butnariu, 2012; Pisoschi, 2015). Synthetic antioxidants, such as BHA, BHT, TBHQ etc., perhaps, are the most extensively used additives for

Copyright $(\odot 2019$ The Authors. Published by Vytautas Magnus University. This is an open-access article distributed under the terms of the Creative Commons Attribution License (CC-BY 4.0), which permits unrestricted use, distribution, and reproduction in any medium, provided the original author and source are credited. 
the rancidity prevention in the food industry (Nanditha, 2008; Anbudhasan, 2014; Hermund, 2018). Some authors summarized the main advantages of their usage. Among them are low price, easy application to food systems, stable quality, antimicrobial effect and greater antioxidant activity compared with natural compounds (Akbarirad, 2016; Nanditha, 2008). At the same time according to the global consumer demands towards clearly labeled products that are totally safe and free of artificial ingredients the addition of synthetic antioxidants in the products recipe causes concerns.

In this case there is an increasing need of the alternative natural raw materials, which provide the flour products quality stabilization with high fat content during storage and potential nutritional effect. It should be mentioned that herbs due to their chemical composition can be the potential source of natural origin antioxidants (Akbarirad, 2016; Ingvild, 2011; Kyung, 2008). In their research Dimov et. Al., (2018) show that adding of herbal mixtures (thyme, oregano and lemon balm) to the wheat flour leads to the antioxidant activity increase of the final wheat products. Herbs enriched bread characterized with higher healthy status and sensory characteristics compared with control sample. Some authors (Das et. Al., 2012) observed that powder coriander leaf usage effects positively on the flour products. Suggested natural raw-material characterized with high content of the polyphenolic compounds and its addition enhances health benefit for the flour products and prolongs their shelf life. In a study by Frutos (2005), the influence of rosemary extract on the bread with an oil and garlic/parsley dressing was evaluated. It is shown that usage of this herb extract retards the rancidity process, which is confirmed with lower peroxide value after 8 days of storage for enriched samples. The supplementation of $1 \ldots 4 \%$ rosemary and mints to the cookie recipe is also the effective way for the antioxidant activity product increase (Myeong-Sook, 2006). The obtained results indicated that $1 \%$ rosemary herb cookies has the highest sensory test characteristics (overall acceptability, taste, etc.).

Despite existing results of herbs usage in bread making, there is lack of the experimental data of the natural antioxidants enrichment of the low-moisture bakery products with high fat content, such as rusk. Currently these types of bakery goods are in a high demand because they are the ideal type of "food on the go" with long term of storage. It should be mentioned that in rusk technology the fats and their oxidative stability play the key role in the quality formation. Due to this the purpose of the study was to determine the effectiveness of herbs (hop, chamomile, nettle) water extracts on the rancidity retardation of the rusks during their storage.

\section{MATERIALS AND METHODS}

The dry leaf of nettle (Urtica dioica) and flower-stalk part of chamomile (Matricária recutíta) were used for water extraction, $10 \mathrm{~g}$ herbs was grounded into a powder in a mill and was mixed with $100 \mathrm{ml}$ boiling water by magnetic stirrer during fifteen minutes, next the extract was filtered over Whatman No.1 paper.

Hop (Humulus lupulus) extract was made in a different way because it needs special condition for extraction of isohumulone, which is the valuable substance in the hop. It has antiseptic properties and takes part in redox reactions. We have used granulated hops type 90 local crop «UA-AROMA». It is a granulated powder of dry hops, ground to a particle size of $1-5 \mathrm{~mm}$. The hop pellets were poured into the water with the temperature of $\left(90-95{ }^{\circ} \mathrm{C}\right.$ in the ratio of $1: 100$, after that it was boiled during $90 \mathrm{~min}$. with slow steering, next the extract was filtered over Whatman No.1 paper. For extraction all herb raw materials, the water were used with next quality characteristics: $\mathrm{pH}=6.7$; hardness $-5.9 \mathrm{mg} / \mathrm{l}$.

The total flavonoids content (TFC) was determined using aluminium chloride colorimetric method according to Chang et. al. (2002). The total flavonoid content was calculated from a calibration curve, and the result was expressed as mg rutin equivalent per $\mathrm{g}$ of dry weight. The vitamin $\mathrm{C}$ concentration was determined in the herbs extract by a redox titration with potassium iodate in the presence of potassium iodide. The method for determining the isohumulone based on isooctane $(2,2$, 4-trimethylpentane) extraction and determination of the optical density of isooctane extract on a spectrophotometer at the wavelength of $275 \mathrm{~nm}$ (Rigby, Bethune, 1955).

Total phenolic content (TPC) of extracts were analyzed as presented in research work of Singleton and Rossi (1965) with some changes. $0.03 \mathrm{ml}$ of all samples was taken in a test tube with $1 \mathrm{ml}$ of distilled water. After that $0.5 \mathrm{ml}$ FolinCiocalteau reagent (1:1) and $10 \mathrm{ml} 7.5 \%$ sodium carbonate solution were added. The contents were mixed and after that incubated under dark at room temperature for $30 \mathrm{~min}$. For blank preparation, $1 \mathrm{ml}$ of distilled water was taken instead of the sample. For determination, was used the spectrophotometer where the absorbance of the samples was measured at $750 \mathrm{~nm}$. These results were converted into $\mathrm{mg}$ of GAE (Gallic acid equivalent) per $100 \mathrm{~g}$.

Rusk for research was made according to "National bakery recipe collection" the recipe of rusk, since the amount of butter in them reached up to $15 \%$. The control sample was prepared according to the recipe, which contained $100 \%$ of wheat all-purpose flour, $15 \%$ of butter, $10 \%$ of sugar, $4 \%$ yeast by weight of dry ingredients, liquid part according to the calculation based on the moisture content of the recipe. The water in the dough recipe was replaced by hop, nettle and chamomile extracts in the amount of $25,50,75 \%$ respectively, according to previous research based on sensor evaluation of baked dough sample. One sample has been prepared with the addition of butylated hydroxyanisole (BHA) $0.01 \%$ by weight of butter in the recipe. The conditions of kneading, proofing and baking were the same as described below. The rusk technology consists of several operations: dough mixing, dough fermentation, forming, proofing, baking, cooling, cutting and drying at $120{ }^{\circ} \mathrm{C}$ during 20 30 min until the moisture content of the rusk decreased to the level 8-9\%. To speed up the rancidity the suggested (used) storage conditions were: no packaging used, the ambient temperature ( $t$ ) was $40 \pm 1^{\circ} \mathrm{C}$, and the relative humidity $(\varphi)$ of the air was $65-70 \%$, with the access of sunlight. 
The fat was separated from the product by solid-liquid extraction using diethyl ether/petroleum ether mixtures $(1: 1 \mathrm{v} / \mathrm{v})$. In particular, ground rusks and solvent mixture in the ratio of $1: 2.5 \mathrm{w} / \mathrm{v}$ were stirred at room temperature for $1 \mathrm{~h}$. After filtration through filter paper (Whatman no. 1), the fat was separated from the solvent by evaporation. Determination of peroxides content was conducted according to ISO 3960:2017 standard method by assaying the peroxide value (PV) with the titration method.

A twenty persons (both male and female) who has experience in sensor assessment were evaluated the rusks aroma profile and flavor were asked to describe aroma and taste in line with next statements "free of any foreign smell and/or taste":, "have foreign smell", "have foreign taste", "have foreign smell and taste". To determine the physical and chemical characteristics of rusks we have used standard DSTU 7045:2009 Bakery products. Methods of determination of physical and chemical characteristics.

Statistical data were processed using Microsoft "Excel" and "STATISTICA 7.0" software packages. The differences between the values were considered to be significant at $\mathrm{p} \leq 0.05$.

\section{RESULTS AND DISCUSSION}

Additives of natural origin based on medicinal and spicy raw materials can be successfully used as inhibitors of biochemical and microbiological processes leading to spoilage of products. Extracts are natural complex of biologically active substances, which include substances with antioxidant and antimicrobial properties that are safer than additives of artificial origin.

Phenolic compounds have redox properties that allow them to act as antioxidants (Soobrattee, M.A., et. al., 2005). The most important property of phenolic and polyphenolic compounds is their participation in redox reactions and in the process of neutralization of reactive oxygen species. Herbs have a different chemical compound, but all of them contain polyphenols, flavonoids, which are well known as substances with antioxidant activity. The vitamin $\mathrm{C}$ is also considered one of the most active antioxidants (Kukrić, Z. Z. et al., 2012).

In order to establish patterns of relationship between the composition-concentration of active ingredients of herbs extracts such as TFC, TPC, Vitamin C, Isohumulon, and the speed of the rancidity in the bakery products with low-moisture content which have been determined in extracts (Table 1). Since vitamin C is present in large quantities in nettles, its presence was determined only for this extract, a similar for the determination of isohumulone.

Table 1. The content of substances with antioxidant activity in extracts

\begin{tabular}{|l|c|c|c|c|}
\hline Sample & $\begin{array}{c}\text { Total flavonoid content, } \\
\text { mg rutin eq. } 100 \mathrm{~g} \mathrm{~g}^{-1} \\
\text { DW }\end{array}$ & $\begin{array}{c}\text { Total phenolic content, } \\
\text { Gallic acid eq. } 100 \mathrm{~g}^{-1} \\
\text { DW }\end{array}$ & $\begin{array}{c}\text { Vitamin C, mg 100 } \\
\mathrm{g}^{-1} \\
\text { DW }\end{array}$ & $\begin{array}{c}\text { Isohumulon, } \\
\mathrm{mg}_{\left(\mathrm{dm}^{3}\right)^{-1}}\end{array}$ \\
\hline Hop extract & 23,2 & 67,4 & wasn't an object & 135 \\
\hline Chamomile extract & 5,7 & 18,3 & wasn't an object & wasn't an object \\
\hline Nettle extract & 11,2 & 48 & 0,87 & wasn't an object \\
\hline
\end{tabular}

The results show that hop extract has more TPC than nettle and chamomile extracts. This result can be explained by the fact that hop polyphenolic substances have high antioxidant properties, dissolve in water at any temperature and, as shown by research in the brewing industry, retain their activity after brewing (Knez Hrnčič, 2019). The research work (Pereira, 2018), in which the total content of phenolic compounds in chamomile was studied, obtained comparable results. An insignificant content of vitamin $\mathrm{C}$ was found in the finished nettle extract, which is most likely due to the temperature conditions of extraction, Rutto et. al. (2013) and Wolska, (2016) reported a loss of ascorbic acid from $1.1 \mathrm{mg}^{100 \mathrm{~g}^{-1}}$ in fresh leaves to 0.6 $\mathrm{mg} 100 \mathrm{~g}^{-1}$ in cooked leaves. Considering the fact that it is necessary to provide antioxidant activity in baked and dried flour products undergoing severe temperature conditions, the predicted result will be the loss of almost the entire extracted vitamin C. From our point of view, in such situation, it is still worth concentrating on polyphenolic compounds.

The content of substances with antioxidant properties is influenced by both the extraction conditions and the region of origin of certain herbs, nevertheless, the aim of this work was to study the possibility of using the simplest extraction conditions to obtain plant extracts containing a sufficient amount of antioxidant substances and capable of compete with synthetic antioxidants. According to (Kukrić, 2012), ethanol nettle extract had a 20 times weaker total antioxidant ability compared to control antioxidants such as vitamin $\mathrm{C}$ and BHA (butylated hydroxyanisole). At the same time, according to (Gülçin, 2004), nettle extract was more active in absorbing superoxide radicals than BHA. It is quite difficult to compare the total antioxidant activity in the simulated systems; it is even more difficult to predict the effect that the extracts will have on the final product; therefore, it seemed necessary for us to evaluate the result of their action in the final products.

Changes in the lipid component that lead to rancidity can be associated or accompanied by an increasing of their moisture content and acidity. These indexes were studied in assessing the properties of finished products, which are shown in table 2.

An increase in titratable acidity occurs as a result of the accumulation of organic acids and acid-reactive compounds formed during oxidative hydrolytic processes occurring with lipids. The titratable acidity for all storage samples increased compared to the initial value but the intensity of these processes was different. Thus, the increase in titratable acidity relative 
to the starting point was $28 \%$ for the control, $17 \%$ for the sample with chamomile extract, $7 \%$ for the sample with nettle extract, and 3\% for the sample with BHA. The only sample that did not change its performance relative to the starting point was a sample with hop extract. Obtained data naturally correlates with a significant content of polyphenolic compounds in comparison with other extracts that were selected for research.

Table 2. Characteristics of rusks

\begin{tabular}{|c|c|c|c|c|c|}
\hline Storage time in special conditions & Control & With hop extract & $\begin{array}{c}\text { With chamomile } \\
\text { extract }\end{array}$ & $\begin{array}{l}\text { With nettle } \\
\text { extract }\end{array}$ & $\begin{array}{l}\text { With } 0.01 \% \text { butylated } \\
\text { hydroxyanisole (BHA) }\end{array}$ \\
\hline \multicolumn{6}{|c|}{ Titratable acidity, ${ }^{\circ} \mathrm{H}$} \\
\hline $1^{\text {st }}$ day & 2,8 & 2,8 & 2,8 & 2,8 & 2,8 \\
\hline After 2 weeks & 2,8 & 2,8 & 2,8 & 2,8 & 2,8 \\
\hline After 4 weeks & 2,8 & 2,8 & 2,8 & 2,8 & 2,8 \\
\hline After 6 weeks & 3,2 & 2,8 & 3,0 & 3,0 & 2,9 \\
\hline After 8 weeks & 3,6 & 2,8 & 3,3 & 3,0 & 2,9 \\
\hline \multicolumn{6}{|c|}{ Moisture content, $\%$} \\
\hline $1^{\text {st }}$ day & 9,0 & 9,0 & 8,8 & 9,0 & 9,0 \\
\hline After 2 weeks & 9,2 & 9,2 & 8,8 & 9,0 & 9,0 \\
\hline After 4 weeks & 9,2 & 9,2 & 8,8 & 9,0 & 9,0 \\
\hline After 6 weeks & 9,5 & 9,3 & 8,8 & 9,3 & 9,2 \\
\hline After 8 weeks & 9,5 & 9,3 & 9,0 & 9,3 & 9,2 \\
\hline \multicolumn{6}{|c|}{ Sensor evaluation } \\
\hline $1^{\text {st }}$ day & \multicolumn{5}{|c|}{ free of any foreign smell and/or taste } \\
\hline After 2 weeks & \multicolumn{5}{|c|}{ free of any foreign smell and/or taste } \\
\hline After 4 weeks & \multicolumn{5}{|c|}{ free of any foreign smell and/or taste } \\
\hline After 6 weeks & $\begin{array}{l}\text { foreign } \\
\text { smell }\end{array}$ & \multirow{2}{*}{$\begin{array}{c}\text { free of any } \\
\text { foreign } \\
\text { smell and/or taste }\end{array}$} & foreign smell & \multirow{2}{*}{$\begin{array}{l}\text { free of any } \\
\text { foreign } \\
\text { smell and/o } \\
r \text { taste }\end{array}$} & \multirow{2}{*}{$\begin{array}{l}\text { free of any foreign } \\
\text { smell and/or taste }\end{array}$} \\
\hline After 8 weeks & $\begin{array}{l}\text { foreign } \\
\text { smell and } \\
\text { taste }\end{array}$ & & $\begin{array}{c}\text { foreign } \\
\text { smell and taste }\end{array}$ & & \\
\hline
\end{tabular}

Deterioration of sensory characteristics in the control sample and the sample with chamomile extract may indirectly indicate the formation of reaction products such as aldehydes, ketones, acids, and alcohols. Since, as lipids are oxidized, hydroperoxides are formed, which are the subjects to further oxidation or decomposition to the aforementioned secondary reaction products. It is these compounds, which negatively effect on the taste, aroma, nutritional value and overall quality of the products. High molecular fatty acids have no taste or smell, and therefore, with increasing of their amount in the product, there is no noticeable change. Because of the action of oxygen in fats, primary and secondary oxidation products accumulate. Their presence causes the appearance of a characteristic unpleasant taste and smell in fats. The number of peroxides and hydroperoxides characterizes the peroxide number determined in the samples and shown in Fig. 1.

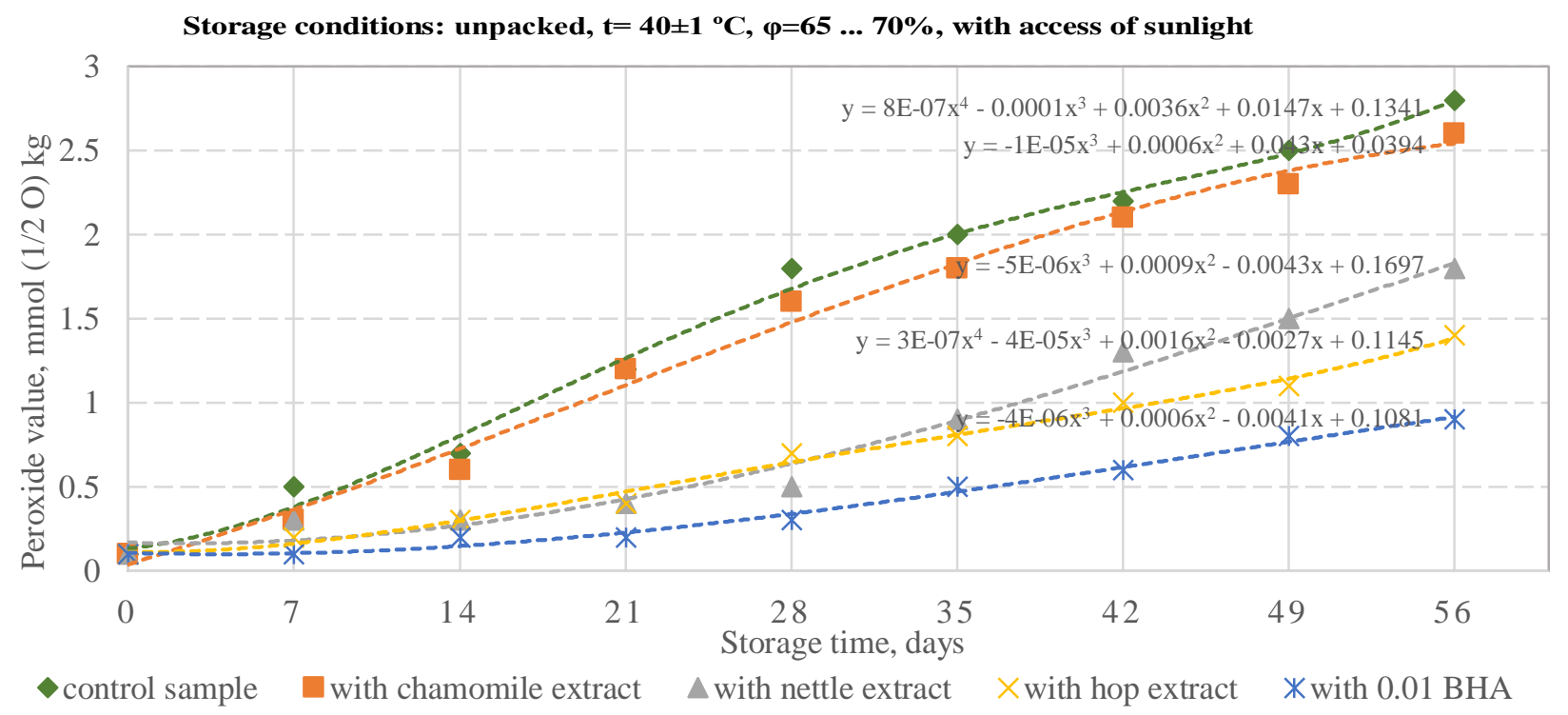

Figure 1. Dynamics of change of lipid peroxide value during special storage conditions 
The dynamics of changes peroxide value during storage in bakery products with low moisture content showed that the oxidation processes in the control sample proceeded more intensively than in the sample with the addition of herbs extracts and BHA. It was noted that the hop extract usage was more effective compared with other extracts but less effective than synthetic BHA. The obtained results are naturally consistent with both the data on the assessment of sensory characteristics and overlap with the quantitative content of polyphenolic substances, the more they were found in extracts, the lower the final peroxide value of fat in the product on the 56th day of storage was.

\section{CONCLUSIONS}

The obtained data suggest that the extracts of the selected herbs do not_exclude, prevent the process of fat oxidation during storage of products; nevertheless, they can significantly inhibit them. This process is more effective the more polyphenols and flavonoids they contain. It has been found that synthetic antioxidants such as BHA can be more effective, in comparison with herbal extracts with a low content of flavonoids and phenolic compounds, in preventing oxidation in the finished product during storage.

The use of natural plant ingredients as a method of inhibiting oxidative spoilage of products will not only have a positive effect on consumer health, but also allow enterprises to follow the trend of a clean label that will bring significant economic benefits.

Further research should be aimed not only for rancidity prevention in products with a low moisture and a high fat content by using natural antioxidants derived from plant extracts, but at studying the technological aspects of their use, as well as the problems of rational dosage of such raw materials.

It seems possible to use a strategy to improve extraction parameters or to create a combination of various extracts to enhance their activity against hydrolytic fat spoilage in low-moisture flour-based products for long-term preservation, their nutritional value and consumer properties.

\section{REFERENCES}

1. Ahmed M., J. Pickova T. Ahmad M. Liaquat A. Farid M. Jahangir. 2016. Oxidation of lipids in foods. Sarhad Journal of Agriculture, Vol. 32, Iss. 3, pp. 230-238. http://dx.doi.org/10.17582/journal.sja/2016.32.3.230.238

2. Akbarirad H., Ardabili A., Kazemeini S.M., Mousavi K.A. 2016. An overview on some of important sources of natural antioxidants. International Food Research Journal, Vol. 23, Iss. 3, pp. 928-933.

3. Anbudhasan P., Surendraraj A., Karkuzhali S., Sathishkumaran P. 2014. Natural antioxidants and its benefits. International Journal of food and nutritional scienes, Vol. 3(6), pp. 225-232.

4. Butnariu M., Grozea I. 2012 Antioxidant (Antiradical) Compounds. Journal of Bioequivalence \& Bioavailability, Vol. 4(6), pp. 17-19. https://doi.org/10.4172/jbb.10000e18

5. Chang C., Yang M., Wen H., Chern J. 2002. Estimation of total flavonoid content in propolis by two complementary colorimetric methods. Journal of Food and Drug Analysis, Vol. 10, pp. 178-182.

6. Cauvain S. 2015. Technology of Breadmaking. 3rd ed., Springer, New York https://doi.org/10.1007/978-3-319-14687-4

7. Das L., Raychaudhuri U., Chakraborty R. 2012. Effect of baking conditions on the physical properties of herbal bread using RSM. International Journal of Food, Agriculture and Veterinary Sciences, Vol. 2, Iss. 2, pp. 106-114.

8. Das L., Raychaudhuri U., Chakraborty R. 2012. Supplementation of common white bread by coriander leaf powder. Food Science and Biotechnology, Vol. 21, Iss. 2, pp. 425-433. https://doi.org/10.1007/s10068-012-0054-9

9. Dhartiben B., Bhumika K., Kishorkumar D. 2016. Spices and herbs as a source of natural antioxidants for food. International Journal of Current Microbiology and Applied Sciences, Vol. 7, pp. 280-288. https://doi.org/10.20546/ijcmas.2016.507.029

10. Dimov I., Petkova N., Nakov G., Tanev I., Ivanov I., Stamatovska V. 2018. Improvement of antioxidant potential of wheat flours and breads by addition of medicinal plants. Ukrainian Food Journal, Vol. 7, Iss. 4, pp. 671-681. https://doi.org/10.24263/2304-974X-2018-7-4-11

11. Frankel E.N. 2012. Antioxidants in food and biology- Facts and fiction. Woodhead Publishing in Food Science, Technology and Nutrition, USA.

12. Frutos M. J., Hernández-Herrero J. A. 2005. Effects of rosemary extract (Rosmarinus officinalis) on the stability of bread with an oil, garlic and parsley dressing. LWT - Food Science and Technology, Vol. 38, Iss. 6, pp. 651-655. https://doi.org/10.1016/j.lwt.2004.08.013

13. ISO 3960:2017. Animal and vegetable fats and oils — Determination of peroxide value — Iodometric (visual) endpoint determination. - 2017.

14. Gülçin I., Küfrevioğlu Ö. İ., Oktay M., \& Büyükokuroğlu M. E. 2004. Antioxidant, antimicrobial, antiulcer and analgesic activities of nettle (Urtica dioica L.). Journal of ethnopharmacology, Vol. 90, Iss. 2-3, pp. 205-215. https://doi.org/10.1016/j.jep.2003.09.028

15. Hebeda R., Zobel H. 1996. Baked Goods Freshness: Technology, Evaluation, and Inhibition of Staling, 1st ed., Marcel Dekker, New York

16. Hermund B. 2018. Antioxidant Properties of Seaweed-Derived Substances. Bioactive Seaweeds for Food Applications. Natural Ingredients for Healthy Diets, 1 st ed., Academic Press. https://doi.org/10.1016/B978-0-12-813312-5.00010-8

17. Ingvild P., Carlsen M. H., Halvorsen B. L., Blomhoff R.. 2011. Herbal Medicine: Biomolecular and Clinical Aspect, 2nd ed., CRS Press

18. Knez Hrnčič, M., Španinger E., Košir I. J., Knez Ž., Bren U. 2019. Hop Compounds: Extraction Techniques, Chemical Analyses, Antioxidative, Antimicrobial, and Anticarcinogenic Effects. Nutrients, Vol. 11, Iss. 2, pp. 1-37. https://doi.org/10.3390/nu11020257

19. Koie K., Itoga Y., Suda N., Ogushi, K. 2016. Construction and Demonstration of a Standardized Hop Boiled Water Extraction Method and its Application for a Sensory Evaluation System of Hop Aroma Characteristics. Journal of the American Society of Brewing Chemists, Vol. 74, Iss. 3, pp. 183-190. https://doi.org/10.1094/ASBCJ-2016-3664-01 
20. Kukrić Z. Z., Topalić-Trivunović L. N., Kukavica B. M., Matoš S. B., Pavičić S. S., Boroja M. M., Savić A. V. 2012. Characterization of antioxidant and antimicrobial activities of nettle leaves (Urtica dioica L.). Apteff, Vol. 43, pp. 257-272. https://doi.org/10.2298/APT1243257K

21. Kyung M. Y., Choong H. L., Hyungjae L., Bo, K., Moonc C., Yong L. 2008. Relative antioxidant and cytoprotective activities of common herbs. Food Chemistry, Vol. 106, Iss. 3, pp. 929-936. https://doi.org/10.1016/j.foodchem.2007.07.006

22. Myeong-Soo, J., Hyun-Duk K. 2006. The foretasting experience of herbs and the sensory characteristics of cookies with rosemary and mints. Culinary science and hospitality research, Vol. 12, Iss. 2, pp. 222-235).

23. Nanditha B., Prabhasankar P. 2008. Antioxidants in Bakery Products: A Review. Critical Reviews in Food Science and Nutrition, Vol. 49 , Iss. 1, pp. 1-27. https://doi.org/10.1080/10408390701764104

24. Pereira S. V., Reis R. A., Garbuio D. C., de Freitas L. A. P. 2018. Dynamic maceration of Matricaria chamomilla inflorescences: Optimal conditions for flavonoids and antioxidant activity. Revista Brasileira de Farmacognosia, Vol. 28, Iss. 1, pp. 111-117. https://doi.org/10.1016/j.bjp.2017.11.006

25. Pisoschi A. M., Pop A. 2015. The role of antioxidants in the chemistry of oxidative stress: A review. European Journal of Medicinal Chemistry, Vol. 97, pp. 55-74. https://doi.org/10.1016/j.ejmech.2015.04.040

26. Ramis-Ramos G. 2003. Encyclopedia of Food Sciences and Nutrition, 2nd ed., Elsevier Science Ltd.

27. Rutto L.K., Xu Y., Ramirez E., Brandt M. 2013. Mineral properties and dietary value of raw and processed stinging nettle (Urtica dioica L.). International Journal of Food Science, Vol. 2013, pp. 1-9. https://doi.org/10.1155/2013/857120

28. Rigby F. L., Bethune J. L. 1955. Rapid methods for the determination of total hop bitter substances (iso-compounds) in beer. Journal of the Institute of Brewing, Vol. 61, Iss. 4, pp. 325-332. https://doi.org/10.1002/j.2050-0416.1955.tb02804.X

29. Singleton V. L., Rossi J. A. 1965. Colorimetry of total phenolics with phosphomolybdic-phosphotungstic acid reagents. American journal of Enology and Viticulture, Vol. 16, Iss. 3, pp. 144-158.

30. Soobrattee M. A., Neergheen V. S., Luximon-Ramma A., Aruoma O. I., Bahorun T. 2005. Phenolics as potential antioxidant therapeutic agents: mechanism and actions. Mutation Research/Fundamental and Molecular Mechanisms of Mutagenesis, Vol. 579, Iss. 1-2, pp. 200-213. https://doi.org/10.1016/j.mrfmmm.2005.03.023

31. Wolska J., Czo, M., Jakubczyk K., Janda K. 2016. Influence of temperature and brewing time of nettle (Urtica dioica L.) infusions on vitamin C content. Roczniki Państwowego Zakładu Higieny, Vol. 67, Iss. 4. 